\title{
Evaluation of clinical and laboratory parameters used in the identification of index cases for genetic screening of familial hypercholesterolemia in Brazil
}

\author{
Pãmela R.S. Silva ${ }^{a}{ }^{*}$, Cinthia E. Jannes ${ }^{a}$, Theo G.M. Oliveira ${ }^{a}$, Marcio H. Miname ${ }^{\text {b }}$, \\ Viviane Z. Rocha ${ }^{\text {b }}$, Ana Paula Chacra ${ }^{b}$, Maria Helane C. Gurgel ${ }^{\text {c }}$, Renan M. Montenegro ${ }^{\text {c }}$ \\ Carlos Roberto M. Rodrigues Sobrinho ${ }^{c}$, Annie Seixas Bello Moreira ${ }^{\mathrm{d}}$,

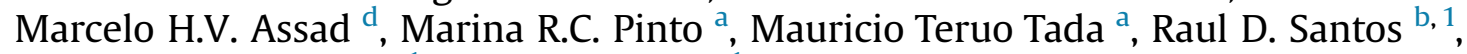 \\ Alexandre C. Pereira ${ }^{a, 1}$, Jose E. Krieger ${ }^{\text {a, } 1}$ \\ ${ }^{a}$ Laboratory of Genetics and Molecular Cardiology, Heart Institute (InCor), University of São Paulo Medical School Hospital, São Paulo, Brazil \\ ${ }^{\mathrm{b}}$ Lipid Clinic, Heart Institute (InCor), University of São Paulo Medical School Hospital, São Paulo, Brazil \\ c Cardiology Department, Walter Cantídio University Hospital, Federal University of Ceara, Fortaleza, Brazil \\ d Cardiology Department, National Institute of Cardiology, Rio de Janeiro, Brazil
}

\section{A R T I C L E I N F O}

\section{Article history:}

Received 12 April 2017

Received in revised form 30 May 2017

Accepted 21 June 2017

Available online 22 June 2017

\section{Keywords:}

Familial hypercholesterolemia Low-density lipoprotein cholesterol

Screening

Index patient

\begin{abstract}
A B S T R A C T
Background and aims: There is controversy on the accuracy of different diagnostic criteria for familial hypercholesterolemia (FH). The aim of this study is to assess the performance of different clinical criteria used to identify individuals for FH genetic cascade screening in Brazil.

Methods: All index cases (IC) registered in the Hipercol Brasil program between 2011 and 2016 were analyzed. Inclusion criteria were age $\geq 18$ years and elevated LDL-cholesterol (LDL-C) levels, with a conclusive result in the genetic test, whether positive or negative. Initially, we tested the multivariable association between clinical and laboratory markers and the presence of an FH causing mutation. Then, we analyzed sensitivity, specificity, positive and negative predictive values for the LDL-C quartile distribution, LDL-C as a continuous variable, as well as the performance measures for the Dutch Lipid Clinic Network (DLCN) score to identify a mutation.

Results: Overall, 753 ICs were included and an FH causing mutation was found in $34 \%(n=257)$ of the subjects. After multivariable analysis, LDL-C as a continuous variable, tendon xanthomas and corneal arcus were independently associated with the presence of $\mathrm{FH}$ mutations. LDL-C values $\geq 230 \mathrm{mg} / \mathrm{dL}$ $(5.9 \mathrm{mmol} / \mathrm{L})$ had the best tradeoff between sensitivity and specificity to diagnose a mutation. The DLCN score presented a better performance than LDL-C to identify a mutation, area under the ROC curve were 0.744 (95\% CI: $0.704-0.784$ ) and 0.730 (95\% CI: 0.687-0.774), respectively, $p=0.014$.
\end{abstract}

Conclusions: In our population, $\mathrm{LDL} \geq 230 \mathrm{mg} / \mathrm{dL}$ is a feasible criterion to indicate ICs to genetic testing. () 2017 Published by Elsevier Ireland Ltd.

\section{Introduction}

Familial hypercholesterolemia (FH) is an autosomal dominant genetic disorder caused by variants that alter LDL-cholesterol (LDL-

Abbreviations: $\mathrm{M}+$, mutation positive; $\mathrm{M}-$, mutation negative; IC, index case; $\mathrm{FH}$, familial hypercholesterolemia; ASCVD, atherosclerotic cardiovascular disease.

* Corresponding author. Av. Dr. Enéas de Carvalho Aguiar, 44 - Cerqueira Cesar, São Paulo, SP, 05403-900, Brazil.

E-mail address: pam_r_s@usp.br (P.R.S. Silva).

1 These authors are last co-authors of the manuscript.
C) catabolism, leading to elevated blood cholesterol levels and consequently increasing the risk of atherosclerotic cardiovascular disease (ASCVD) development. In addition, due to the long-term exposure to high LDL-C, individuals with $\mathrm{FH}$ may present clinical signs that indicate the presence of tendon xanthomas, corneal arcus (when present in individuals aged $\leq 45$ years), and xanthelasmas [1].

Currently, there are about 1600 mutations described as causing $\mathrm{FH}$, with $95 \%$ of them occurring in the gene coding for the LDL receptor $(L D L R)$. The remaining $5 \%$ affect genes coding for apolipoprotein $\mathrm{B}(A P O B)$ and proprotein convertase subtilisin/kexin type 9 
(PCSK9) [2,3].

$\mathrm{FH}$ is an underdiagnosed and undertreated disease [4] and heterozygous FH is estimated to affect up to 670,000 Brazilians [5]. The diagnosis and treatment of $\mathrm{FH}$ could change the prevalence scenario of ASCVD at early ages since LDL-C lowering treatment has been shown to reduce cardiovascular disease incidence and mortality $[6,7]$.

Diagnosis of FH individuals may be cost-effectively performed through genetic cascade screening programs [7]. Cascade screening methods consist in the identification of an index case (IC), which, because of its high a priori probability of harboring a causal mutation, is then referred to genetic test and, in case of a positive result (i.e. an identified causal genetic mutation), all first-degree relatives are screened for the same mutation. Despite being the most costeffective method, it depends on the assertive identification of an IC, which is itself based on clinical criteria [8]. In the literature, the most adopted clinical classifiers for $\mathrm{FH}$ are from the Simon Broome Register Group [9] and the Dutch Lipid Clinic Network (DLCN) [10]; however, there is no international consensus on which are the best clinical predictors to refer patients for genetic test. This is particularly relevant if one considers the different settings from which ICs may be referred (direct-consumer, primary care, secondary care) and the different availability of detailed laboratory and clinical information on them. Therefore, population-specific adjustments are frequently observed in the literature [11,12].

The accuracy of specific clinical or biochemical parameters may change from one setting to another and the overall costeffectiveness of cascade screening programs depends on the balance between sensitivity and specificity testing for the IC. Therefore, in this study, we assessed the accuracy of different $\mathrm{FH}$ diagnostic clinical criteria in the Hipercol Brasil [5], a state of the art genetic cascade-screening program.

\section{Materials and methods}

This study was performed with subjects registered in an $\mathrm{FH}$ genetic cascade screening program in Brazil. Participants were recruited by doctors from the Heart Institute (InCor), University of Sao Paulo Medical School or from partner institutions. In addition, individuals, who contacted the program via website, were also selected by trained health professionals from the program. After inclusion criteria were met, participants were referred to genetic testing.

The program is conducted at the Laboratory of Genetics and Molecular Cardiology at the Heart Institute (InCor/HCFMUSP), University of São Paulo Medical School Hospital, São Paulo, Brazil. The study was approved by the Institutional Ethics Committee (CAPPesq number 3757/12/013), and all subjects signed an informed consent form.

\subsection{Study population and inclusion criteria}

We included in this analysis all IC individuals registered in Hipercol Brasil between 2011 and 2016. The inclusion criteria for this study were: age $\geq 18$ years and a conclusive result of the genetic test, whether positive or negative. The only inclusion criterion for being registered at Hipercol Brasil was to have previous documentation of an LDL-C $\geq 210 \mathrm{mg} / \mathrm{dL}$. However, some individuals with LDL-C values $\leq 210 \mathrm{mg} / \mathrm{dL}$ were also included in the program during the selected period, when referred by local physicians due to other overwhelming clinical characteristics associated with FH.

\subsection{Clinical and laboratory characteristics}

All relevant clinical information was collected through a standardized questionnaire and physical exams followed by the collection of biological material as previously described [5]. Subjects were examined for the presence of xanthomas, xanthelasmas or corneal arcus. Weight $(\mathrm{kg})$ and height $(\mathrm{m})$ were determined and the body mass index (BMI in $\mathrm{kg} / \mathrm{m}^{2}$ ) was calculated. Laboratorial exams were obtained from medical records or from previous exams brought by the participants. Values of fasting total cholesterol (TC), LDL-C, HDL-C, and triglycerides (TG) were collected. LDL-C values used were those available at baseline evaluation. When the subject was on statin use, we asked for the highest documented value before statin initiation. In case we could not retrieve that piece of information, the value obtained under statin treatment was used to calculate the scores. The DLNC score was calculated using information available at the baseline visit and, therefore, the presence of an FH causing mutation was not considered for diagnosis.

\subsection{Genetic testing}

Subjects were tested for six FH-related genes: $L D L R, A P O B$, PCSK9, LDLRAP1, LIPA and APOE using state of the art molecular techniques. Target regions were considered as coding exons plus 10 bp of introns up- and downstream. The promoter region of $L D L R$ was also screened. Templates were prepared on Ion One Touch System and sequenced in Ion Torrent $\mathrm{PGM}^{\circledR}$ platform, with 32 samples per run in a 316v2 Ion Chip. Raw FASTQ files were imported into CLC Genomics Workbench 9.5 (QIAGEN) and analyzed using a custom pipeline. Minimum quality requirements for variant call were: base quality of PhredQ $\geq 20$; target-region coverage $\geq 10 x$; frequency of variant allele $\geq 20 \%$ and bidirectional presence of the variant allele. After minor allele frequency filtering $(\mathrm{MAF} \leq 0.002)$ with control populations (NHLBI-ESP6500, ExAC and $1000 \mathrm{Genomes}$ ), all potentially causal variants were consulted for previous description in ClinVar, Human Genome Mutation Database (HGMD ${ }^{\circledR}$ Professional - QIAGEN), British Heart Foundation and Jojo Genetics databases. Pathogenicity attribution was performed according to the American College of Medical Genetics (ACMG) guideline [13].

For previously undescribed variants, functional impact prediction was performed with SIFT, PROVEAN and PolyPhen-2 and variants without previous description were considered as potentially pathogenic when pointed as damaging in at least two algorithms and if $\mathrm{MAF} \leq 0.002$. Individuals with negative results were also screened for large insertions and deletions via MLPA (MRCHolland).

\subsection{Statistical analysis}

Initially, a descriptive analysis of the variables was carried out and results are presented according to the IC's genetic results: mutation positive $(\mathrm{M}+)$ for those in whom a causative genetic variant was identified, and mutation negative (M-) for those without observed causative variants. For continuous variables, the mean and standard deviations were calculated. Categorical variables were described as frequencies. The differences between frequencies were compared using the Chi-square test. The differences between means were compared with Student $t$ or analysis of variance (ANOVA) tests, if necessary. Logistic regression was used to test the independent association of clinical and laboratory variables with the presence of a mutation. The performance (sensitivity, specificity, positive and negative predictive values PPV and NPV, respectively) of different criteria to diagnose the presence of an $\mathrm{FH}$ causing mutation was tested as follows: first, the categorical distribution of LDL-C (25th, 50th and 75th percentiles) within the study population; second LDL-C levels as continuous variables and the best tradeoff between sensitivity and specificity was 
Table 1

Index case (IC) clinical characteristics according to the presence or absence of an FH causative mutation.

\begin{tabular}{|c|c|c|c|c|c|}
\hline & \multicolumn{2}{|c|}{ Mutation +} & \multicolumn{2}{|c|}{ Mutation - } & \multirow[t]{3}{*}{$p$ value $^{a}$} \\
\hline & \multicolumn{2}{|c|}{$(\mathrm{n}=257)$} & \multicolumn{2}{|c|}{$(n=496)$} & \\
\hline & & $\mathrm{n}$ & & $\mathrm{n}$ & \\
\hline Age (years) & $50 \pm 15$ & 257 & $52 \pm 13$ & 496 & 0.01 \\
\hline Males (\%) & 39.3 & 101 & 36.7 & 182 & 0.45 \\
\hline Female $(\%)$ & 60.3 & 155 & 63.3 & 314 & \\
\hline Hypertension (\%) & 30.4 & 78 & 48.0 & 238 & 0.01 \\
\hline Diabetes (\%) & 10.1 & 26 & 12.7 & 63 & 0.45 \\
\hline Early coronary artery disease (\%) & 31.1 & 80 & 31.0 & 154 & 0.65 \\
\hline Acute myocardial infarction (\%) & 16.7 & 43 & 18.3 & 91 & 0.95 \\
\hline Angina $(\%)$ & 24.5 & 63 & 22.0 & 109 & 0.16 \\
\hline Family history of increased LDL-C levels $(\%)^{c}$ & 47.1 & 121 & 50.4 & 250 & 0.01 \\
\hline Family history of early coronary artery disease (\%) & 40.5 & 104 & 44.0 & 218 & 0.03 \\
\hline Current pharmacological treatment $(\%)^{e}$ & 81.7 & 210 & 80.8 & 401 & 0.77 \\
\hline BMI $\left(\mathrm{kg} / \mathrm{m}^{2}\right)$ & $27 \pm 5$ & 221 & $27 \pm 5$ & 481 & 0.10 \\
\hline Smoking (\%) & 8.6 & 22 & 14.7 & 73 & 0.05 \\
\hline Tendon xanthoma (\%) & 13.2 & 34 & 1.0 & 5 & 0.01 \\
\hline Xanthelasmas (\%) & 12.5 & 32 & 7.1 & 35 & 0.01 \\
\hline Corneal arcus (\%) & 28.4 & 73 & 13.5 & 67 & 0.01 \\
\hline \multicolumn{6}{|l|}{ DLCN score (\%) } \\
\hline Definitive & 40.9 & 105 & 10.1 & 50 & 0.01 \\
\hline Probable & 28.4 & 73 & 29.2 & 145 & \\
\hline Possible & 22.2 & 57 & 42.7 & 212 & \\
\hline Unlikely & 2.3 & 6 & 12.1 & 60 & \\
\hline
\end{tabular}

${ }^{\mathrm{a}} p<0.05$.

b Coronary disease in men aged under 55 years or women aged under 60 years.

c First or second degree relatives with TC $>260 \mathrm{mg} / \mathrm{dL}$ or LDL $>160 \mathrm{mg} / \mathrm{dL}$ in children (>16 years) or TC $>290 \mathrm{mg} / \mathrm{dL}$ or LDL $>190 \mathrm{mg} / \mathrm{dL}$ in adults (pre-treatment levels or the highest level under treatment).

d Family history of coronary disease (e.g. heart attack) in first or second degree relatives (men aged under 55 years and women aged under 60 years).

e Current use of lipid-lowering drugs (e.g. statins). To transform mg/dL in mmol/L multiply by 0.0256 .

determined by calculating the area under the receiver operation curve (ROC); third the DLCN score; we compared the discriminative value of the DLCN criteria and the best determined LDL-C value by $C$ statistics; finally we calculated the IC's age distribution in our population (25th, 50th and 75th percentiles) and analyzed the best LDL-C cutoff for each age group $(\leq 40,41-51,52-59$ and $\geq 60$ years old) through $C$ statistics. Significance was considered at a $p<0.05$. Statistical analyses were performed using the Statistical Package for Social Sciences (SPSS version 13.0), except for the comparison of discrimination between LDL-C values and the DLCN score that was done using an online tool (http://vassarstats.net).

\section{Results}

Seven hundred and fifty-three ICs were included in the study. Tables 1 and 2 describe clinical and laboratorial characteristics of included individuals. Overall, $34.1 \%(\mathrm{n}=257)$ of screened individuals had a positive mutation identified through genetic screening $(\mathrm{M}+) . \mathrm{M}+$ individuals were significantly younger than M- ICs. The presence of characteristic clinical signs of FH such as xanthomas, xathelasmas and corneal arcus was greater in $\mathrm{M}+$ individuals. There were no differences between the groups regarding the presence of previous ASCVD or lipid lowering therapy. Overall, $40.9 \%$ of the individuals that were classified as a "definitive" diagnostic in the DLNC clinical score had a causal variant identified (Table 1).

Table 2 shows baseline and on-treatment plasma lipids of the studied subjects. The average baseline and on-treatment LDL-C and TC values were higher in $\mathrm{M}+$ individuals. On the other hand, $\mathrm{M}$ individuals presented higher values for both baseline and ontreatment TG.

Table 3 shows that after multivariable logistic regression analysis, the presence of tendon xanthomas, corneal arcus and baseline LDL-C values was independently associated with the presence of an
FH causative mutation. No independent association was found with family history of early ASCVD or elevated LDL-C levels.

Table 4 and Fig. 1 show values for sensitivity, specificity, PPV and NPV of different parameters to select ICs for genetic test. As expected, the higher the LDL-C levels, the greater the specificity and the lower the sensitivity for the presence of an FH causing mutation. LDL-C levels $\geq 230 \mathrm{mg} / \mathrm{dL}(5.9 \mathrm{mmol} / \mathrm{L})$, that coincided with the $50^{\text {th }}$ percentile of the LDL-C distribution of the IC population, had the best tradeoff between sensitivity and specificity to diagnose a mutation as shown in Supplemental Table 1. The DLCN score presented a better discrimination than LDL-C $\geq 230 \mathrm{mg} / \mathrm{dL}$ (5.9 mmol/L) to identify an $\mathrm{FH}$ causing mutation, area under the ROC curve respectively of 0.744 (95\% CI: $0.704-0.784)$ and 0.730 (95\%CI: 0.687-0.774), $\quad p=0.01 \quad$ (Supplemental Fig. 1 and Supplemental Table 1$)$. The LDL-C $\geq 230 \mathrm{mg} / \mathrm{dL}$ cutoff was identified as the best value in the age groups $(\leq 40 ; 41-51 ; 52-59$ year old), except for the elderly group ( $\geq 60$ years), in which the best

Table 2

Index cases lipid values according to the presence or absence of an $\mathrm{FH}$ causative mutation.

\begin{tabular}{|c|c|c|c|c|c|}
\hline & \multicolumn{2}{|l|}{$\begin{array}{l}\text { Mutation }+ \\
(\mathrm{n}=257)\end{array}$} & \multicolumn{2}{|l|}{$\begin{array}{l}\text { Mutation - } \\
(\mathrm{n}=496)\end{array}$} & \multirow[t]{2}{*}{$p$ value } \\
\hline & & $\mathrm{n}$ & & $\mathrm{n}$ & \\
\hline Baseline TC $(\mathrm{mg} / \mathrm{dL})$ & $388 \pm 84$ & 134 & $320 \pm 51$ & 227 & 0.01 \\
\hline On treatment $\mathrm{t}^{\mathrm{b}} \mathrm{TC}(\mathrm{mg} / \mathrm{dL})$ & $340 \pm 107$ & 102 & $302 \pm 53$ & 206 & 0.01 \\
\hline Baseline LDL-C (mg/dl) & $307 \pm 79$ & 127 & $232 \pm 44$ & 217 & 0.01 \\
\hline On treatment LDL-C $(\mathrm{mg} / \mathrm{dL})$ & $265 \pm 105$ & 100 & $216 \pm 45$ & 195 & 0.01 \\
\hline Baseline HDL-C (mg/dL) & $48 \pm 15$ & 125 & $50 \pm 15$ & 211 & 0.40 \\
\hline On treatment HDL-C $(\mathrm{mg} / \mathrm{dL})$ & $46 \pm 13$ & 100 & $50 \pm 15$ & 193 & 0.03 \\
\hline Baseline TG $(\mathrm{mg} / \mathrm{dL})$ & $141 \pm 63$ & 123 & $187 \pm 106$ & 208 & 0.01 \\
\hline On treatment $\mathrm{TG}(\mathrm{mg} / \mathrm{dL})$ & $144 \pm 72$ & 100 & $190 \pm 119$ & 189 & 0.01 \\
\hline
\end{tabular}

a $p<0.05$.

b With use of lipid-lowering drugs. To transform $\mathrm{mg} / \mathrm{dL}$ in $\mathrm{mmol} / \mathrm{L}$ multiply by 0.0256 . 
Table 3

Parameters related to the presence of an FH causative mutation.

\begin{tabular}{|c|c|c|c|c|c|c|}
\hline & $\mathrm{OR}^{\mathrm{a}}$ & $95 \% \mathrm{CI}$ & $p$ value $^{\mathrm{b}}$ & $\mathrm{OR}^{\mathrm{c}}$ & $95 \% \mathrm{CI}$ & $p$ value $^{\mathrm{b}}$ \\
\hline Age (years) & 0.98 & $0.97-0.99$ & 0.01 & & & \\
\hline Hypertension & 0.53 & $0.38-0.73$ & 0.01 & & & \\
\hline Family history of early ASCVD & 1.52 & $1.04-2.23$ & 0.03 & & & \\
\hline Family history of increased LDL-C levels & 1.70 & $1.12-2.56$ & 0.01 & & & \\
\hline Tobacco consumption (current) & 0.55 & $0.32-0.92$ & 0.02 & & & \\
\hline Tendon xanthoma & 15.93 & $6.14-41.31$ & 0.01 & 6.06 & $1.86-19.71$ & 0.01 \\
\hline Xanthelasmas & 2.11 & $1.27-3.51$ & 0.01 & & & \\
\hline Corneal arcus & 2.93 & $2.00-4.28$ & 0.01 & 1.76 & $1.00-3.08$ & 0.04 \\
\hline Baseline TC & 1.01 & $1.01-1.02$ & 0.01 & & & \\
\hline Baseline LDL-C & 1.02 & $1.01-1.03$ & 0.01 & 1.01 & $1.00-1.02$ & 0.01 \\
\hline Baseline HDL-C & 0.99 & $0.97-1.01$ & 0.40 & & & \\
\hline Baseline TG & 0.99 & $0.90-0.99$ & 0.01 & & & \\
\hline
\end{tabular}

${ }^{a}$ Univariate logistic regression analysis.

b $p<0.05$.

c Multivariate logistic regression analysis (variables entered on model: age, family history of increased LDL-C levels, family history of ASCVD, baseline LDL-C, tendon xanthoma, corneal arcus).

Table 4

Sensitivity, specificity, positive and negative predictive value (PPV and NPV, respectively) for LDL-C percentiles and the DLNC clinical score.

\begin{tabular}{|c|c|c|c|c|c|c|c|c|}
\hline \multirow{2}{*}{ Score } & \multicolumn{2}{|c|}{ Mutation + } & \multicolumn{2}{|c|}{ Mutation - } & \multirow{2}{*}{$\frac{\text { Sensitivity }}{\%(95 \% \mathrm{CI})}$} & \multirow{2}{*}{$\frac{\text { Specificity }}{\%(95 \% \mathrm{CI})}$} & \multirow{2}{*}{$\frac{\text { PPV }}{\%(95 \% \mathrm{CI})}$} & \multirow{2}{*}{$\frac{\mathrm{NPV}}{\%(95 \% \mathrm{CI})}$} \\
\hline & $\%$ & $\mathrm{n}$ & $\%$ & $\mathrm{n}$ & & & & \\
\hline LDL-C $\geq 205 \mathrm{mg} / \mathrm{dL}$ & 40.4 & 208 & 59.6 & 307 & $87.0(81.9-90.8)$ & $30.3(26.1-34.9)$ & $40.3(36.1-44.7)$ & $81.2(74.2-86.6)$ \\
\hline LDL-C $\geq 230 \mathrm{mg} / \mathrm{dL}$ & 49.6 & 170 & 50.4 & 173 & $71.1(64.8-76.6)$ & $60.7(56.0-65.3)$ & $49.5(44.1-54.9)$ & $79.5(74.7-83.6)$ \\
\hline $\begin{array}{l}\text { LDL-C } \geq 273 \mathrm{mg} / \mathrm{dL} \\
\text { DLNC }\end{array}$ & 68.6 & 118 & 31.4 & 54 & $49.3(42.8-55.8)$ & $87.7(84.2-90.5)$ & $68.6(61.0-75.3)$ & $76.1(72.1-79.7)$ \\
\hline Definitive & 67.7 & 105 & 32.3 & 50 & $43.5(37.2-50.0)$ & $89.2(86.0-91.8)$ & $67.7(59.6-74.8)$ & $75.4(71.5-78.8)$ \\
\hline Probable & 33.5 & 73 & 66.5 & 145 & $53.6(44.9-62.1)$ & $65.2(60.4-69.7)$ & $33.4(27.3-40.2)$ & $81.1(76.5-85.1)$ \\
\hline Possible & 21.2 & 57 & 78.8 & 212 & $90.4(79.7-96.0)$ & $22.0(17.3-27.5)$ & $21.1(16.5-26.6)$ & $90.9(80.6-96.2)$ \\
\hline Unlikely & 9.1 & 6 & 90.9 & 60 & $75.0(35.5-95.5)$ & $31.8(22.5-42.7)$ & $9.0(3.7-19.3)$ & $93.3(76.4-98.8)$ \\
\hline
\end{tabular}

To transform mg/dL in mmol/L multiply by 0.0256 .

LDL-C cutoff was $242 \mathrm{mg} / \mathrm{dL}$ (6.2 mmol/L) (Supplemental Fig. 2 and Supplemental Table 2).

\section{Discussion}

In this study, we assessed clinical and laboratory parameters used in the identification of ICs for genetic screening in a cohort of Brazilian individuals suspected of FH diagnosis. In a 5-year period, 753 ICs were screened with a rate of positive mutation detection of 1:3 using state of the art molecular biology techniques. These numbers represent less than $0.5 \%$ of all estimated cases of $\mathrm{FH}$ in Brazil [5]. DLNC criteria seem to be feasible for the identification of individuals with an FH causing mutation, specifically with a score $>6$. However, LDL-C values $\geq 230 \mathrm{mg} / \mathrm{dL}$ also showed good discrimination and could be used as a sole parameter to screen for the $\mathrm{FH}$ mutation presence in hypercholesterolemic individuals.

In the age group analysis, using LDL-C value as a sole parameter, the cutoff in the elderly group ( $\geq 60$ years) increases when compared to other age groups. This result is understandable since cholesterol tends to increase with age, and older individuals might present with other types of dyslipidemias, which influence LDL-C levels. However, as the aim of the program is to identify positives IC in the youngest age possible, and the group of individuals with more than 60 years corresponds to the 75 th percentile of our population, the majority of our target population would be covered with a $230 \mathrm{mg} / \mathrm{dL}$ cutoff.

Familial genetic cascade screening is considered the most costeffective method for FH identification [16], and it is important for an assertive and early diagnostic both in ICs and relatives. In our study, we could show that even the ICs under treatment usually present high levels of LDL-C when entering the program, indicating an inadequate and ineffective therapy, regardless of a known genetic background. Although genetic testing is important for the cascade screening and for diagnostic confirmation, the adopted treatment and clinical management are based on the phenotype features of each individual, which may be highly variable [17-19].

The cascade necessarily begins with a genetic-positive IC, and the identification of a mutation is strongly associated with the clinical diagnosis [12]. Nonetheless, criteria to establish the most cost-effective cutoff for the selection of to-be-screened ICs are not widely agreed upon. Consequently, different programs worldwide have made adjustments to obtain a more effective screening performance for their populations [12,20].

Considering that defining the best cutoff of a diagnostic test procedure involves trade-offs between sensitivity and specificity, and that molecular testing is not able to capture the entire complexity of the clinical diagnosis (it is rather a tool for cascade screening), we aimed at analyzing the overall accuracy of the tested approaches. It should be highlighted that depending on the specific clinical, economical or societal scenario, different options may be preferred. In our specific case, a balance between a high number of individuals with a positive genetic test and the number of individuals undergoing a still costly procedure is the determinant to consider the strategy. In addition, one must consider the ease by which healthcare providers and even individuals from the general population would be able to self-identify or identify a family member as candidates for screening.

The DLCN score is recommended in different guidelines for $\mathrm{FH}$ diagnosis $[4,11,21]$. However, this score is strongly dependent on a reliable knowledge of family history, laboratory values in relatives, and the presence of clinical signs of cholesterol deposits in the skin and tendons. Indeed, in our study, cholesterol deposit signs were 


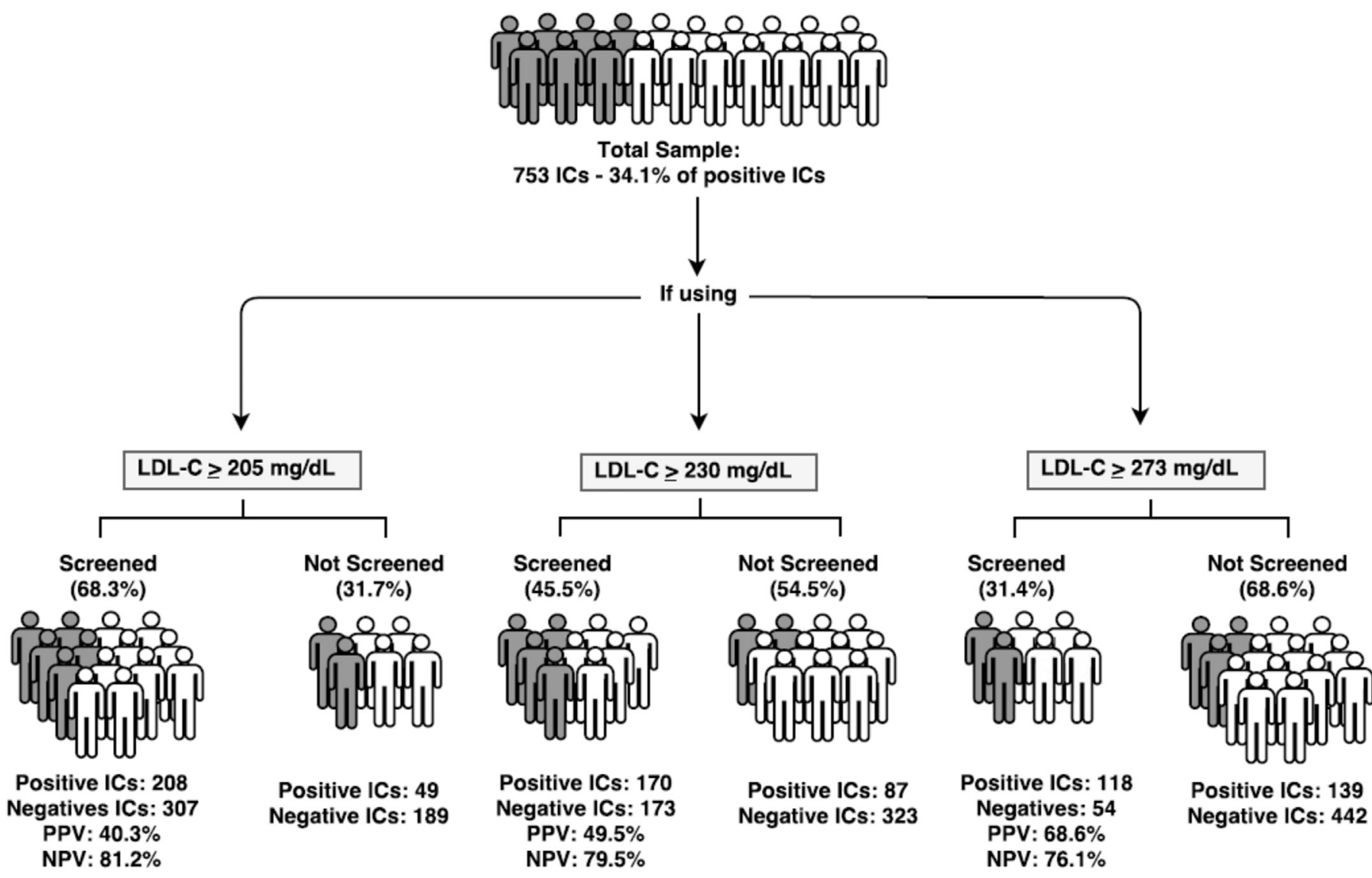

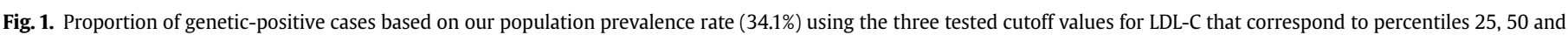
75 for the studied population. Gray shaded individuals represent the percentage of confirmed positive cases while white shaded individuals represent the negative cases.

independently associated with mutation discovery, but they are becoming harder to find nowadays due to the use of lipid lowering therapy for hypercholesterolemia in the absence of an FH diagnosis [19]. In addition, some family information is frequently hard to obtain and usually inaccurate. Indeed, in our study, no independent association was found between family history of early ASCVD or elevated cholesterol levels with mutation finding. Therefore, we believe that the use of an LDL-C threshold could be an alternative to the DLCN score to indicate mutation screening, since previous evidence has suggested that very high blood cholesterol levels are associated with a greater chance of encountering a monogenic cause for the FH phenotype [22].

When comparing the discriminatory performance of DLNC scores with LDL-C values as a criterion for mutation identification, the former presented a better discriminatory performance. However, overall, the proposed LDL-C cutoff value of $230 \mathrm{mg} / \mathrm{dL}$ $(5.9 \mathrm{mmol} / \mathrm{L})$ was a reasonable alternative, with good discrimination capacity.

This study has limitations: first our cohort did not include individuals under 18 years and second, around $80 \%$ of the studied subjects were under statin treatment at the time of the evaluation, and even considering that we used the highest available LDL-C, with or without lipid lowering medications, we can't totally rule out an effect of statin treatment on our results. However, this problem is common to the contemporary FH cohorts, where hypercholesterolemia is diagnosed before FH [23]. Finally, the costeffectiveness of our findings must be tested in a greater number of individuals.

In conclusion, our data suggest that both the DCLN score and a sole criterion of an LDL-C $\geq 230 \mathrm{mg} / \mathrm{dL}$ ( $5.9 \mathrm{mmol} / \mathrm{L}$ ) seem to be adequate for molecular $\mathrm{FH}$ screening in Brazilian individuals. However, using only LDL $\geq 230 \mathrm{mg} / \mathrm{dL}$ is enough to indicate an IC to genetic test, when obtaining some reliable information on all the clinical variables required in DLNC guidelines is often difficult.

\section{Conflict of interest}

RDS refers receiving honoraria for consulting or speaker activities in the last 3 years from Amgen, Aegerion, Astra Zeneca, Akcea, Boehringer-Ingelheim, Biolab, Cerenis, Genzyme, Kowa, Eli-Lilly, Merck, Pfizer, Sanofi/Regeneron, Torrent, Procaps and Unilever. All the other authors have no conflict of interest. We wish to confirm that there are no other known conflicts of interest associated with this publication and there has been no significant financial support for this work that could have influenced its outcome.

\section{Financial support}

The funding of Sociedade Hospital Samaritano and Ministério da Saúde (PROADI-SUS; SIPAR: 25000.180.672/2011-81) and FAPESP (grant no 2013/17368-0) are gratefully acknowledged.

\section{Acknowledgments}

We thank the patients who participated in the cohort study, and the technical assistance of the Laboratory of Genetics and Molecular Cardiology group, Heart Institute (InCor) University of Sao Paulo Medical School Hospital. 


\section{Appendix A. Supplementary data}

Supplementary data related to this article can be found at http:// dx.doi.org/10.1016/j.atherosclerosis.2017.06.917.

\section{References}

[1] R.D. Santos, A.C. Gagliardi, H.T. Xavier, A. Casella Filho, D.B. Araujo, et al., First brazilian guidelines for familial hypercholesterolemia, Arq. Bras. Cardiol. 99 (2012) 1-28. S0066-782X2012001700001 [pii].

[2] M.A. Austin, Genetic causes of monogenic heterozygous familial hypercholesterolemia: a HuGE prevalence review, Am. J. Epidemiol. 160 (2004) 407-420, http://dx.doi.org/10.1093/aje/kwh236.

[3] S.E. Humphries, R.A. Whittall, C.S. Hubbart, S. Maplebeck, J.A. Cooper, et al. Genetic causes of familial hypercholesterolaemia in patients in the UK: relation to plasma lipid levels and coronary heart disease risk, J. Med. Genet. 43 (2006) 943-949, http://dx.doi.org/10.1136/jmg.2006.038356, 43/12/943 [pii].

[4] B.G. Nordestgaard, M.J. Chapman, S.E. Humphries, H.N. Ginsberg, L. Masana, et al., Familial hypercholesterolaemia is underdiagnosed and undertreated in the general population: guidance for clinicians to prevent coronary heart disease, Eur. Heart J. 34 (2013) 3478-3490, http://dx.doi.org/10.1093/eurheartj/ eht273.

[5] C.E. Jannes, R.D. Santos, P.R. de Souza Silva, L. Turolla, A.C.M. Gagliardi, et al., Familial hypercholesterolemia in Brazil: cascade screening program, clinical and genetic aspects, Atherosclerosis 238 (2015) 101-107, http://dx.doi.org/ 10.1016/j.atherosclerosis.2014.11.009. S0021-9150(14)01572-X [pii].

[6] L. Mundal, M.B. Veierod, T. Halvorsen, K.B. Holven, L. Ose, et al., Cardiovascular disease in patients with genotyped familial hypercholesterolemia in Norway during 1994-2009, a registry study, Eur. J. Prev. Cardiol. (2016), http:/| dx.doi.org/10.1177/2047487316666371, 2047487316666371.

[7] R.D. Santos, S.S. Gidding, R.A. Hegele, M.A. Cuchel, P.J. Barter, et al., Review defining severe familial hypercholesterolaemia and the implications for clinical management: a consensus statement from the international atherosclerosis society severe familial hypercholesterolemia panel, LANCET Diabetes Endocrinol. 8587 (2016) 19-21, http://dx.doi.org/10.1016/S2213-8587(16) 30041-9.

[8] R. Henderson, M. O'Kane, V. McGilligan, S. Watterson, The genetics and screening of familial hypercholesterolaemia, J. Biomed. Sci. 23 (2016) 39, http://dx.doi.org/10.1186/s12929-016-0256-1.

[9] Risk of fatal coronary heart disease in familial hypercholesterolaemia, Group scientific steering committee on behalf of the Simon Broome register, BMJ 303 (1991) 893-896. http://www.ncbi.nlm.nih.gov/entrez/query.fcgi? $\mathrm{cmd}=$ Retrieve $\& \mathrm{db}=$ PubMed\&dopt=Citation\&list_uids $=1933004$.

[10] J.C. Desfeche, Familial hypercholesterolemia, in: E.J. Betteridge (Ed.), Lipids Vasc. Dis, 2000th ed., 2000, pp. 65-76. London, United Kingdom.

[11] S.S. Gidding, M.A. Champagne, S.D. De Ferranti, J. Defesche, M.K. Ito, et al., The agenda for familial hypercholesterolemia: a scientific statement from the american heart association, Circulation 132 (2015) 2167-2192, http:/ dx.doi.org/10.1161/CIR.0000000000000297.

[12] K. Haralambos, S.D. Whatley, R. Edwards, R. Gingell, D. Townsend, et al. Clinical experience of scoring criteria for Familial Hypercholesterolaemia (FH) genetic testing in Wales, Atherosclerosis 240 (2015) 190-196, http:/ dx.doi.org/10.1016/j.atherosclerosis.2015.03.003.

[13] S. Richards, N. Aziz, S. Bale, D. Bick, S. Das, et al., Standards and guidelines for the interpretation of sequence variants: a joint consensus recommendation of the american College of medical genetics and Genomics and the association for molecular pathology, Genet. Med. 17 (2015) 405-423, http://dx.doi.org/ 10.1038/gim.2015.30.

[16] Z. Ademi, G.F. Watts, J. Pang, E.J. Sijbrands, F.M. van Bockxmeer, P. O'Leary, E. Geelhoed, D. Liew, Cascade screening based on genetic testing is costeffective: evidence for the implementation of models of care for familial hypercholesterolemia, J. Clin. Lipidol. 8 (2014) 390-400, http://dx.doi.org 10.1016/j.jacl.2014.05.008. S1933-2874(14)00233-5 [pii].

[17] M. Farnier, E. Bruckert, Severe familial hypercholesterolaemia: current and future management, Arch. Cardiovasc Dis. 105 (2012) 656-665, http:/ dx.doi.org/10.1016/j.acvd.2012.05.011. S1875-2136(12)00204-5 [pii].

[18] D.A. Bell, J. Pang, S. Burrows, T.R. Bates, F.M. van Bockxmeer, A.J. Hooper, P. O'Leary, J.R. Burnett, G.F. Watts, Effectiveness of genetic cascade screening for familial hypercholesterolaemia using a centrally co-ordinated clinical service: an Australian experience, Atherosclerosis 239 (2015) 93-100, http:/ dx.doi.org/10.1016/j.atherosclerosis.2014.12.036. S0021-9150(14)01658-X [pii].

[19] P.R.S. Silva, C.E. Jannes, J.D.C. Marsiglia, J.E. Krieger, R.D. Santos, A.C. Pereira, Predictors of cardiovascular events after one year of molecular screening for Familial hypercholesterolemia, Atherosclerosis 250 (2016) 144-150, http:// dx.doi.org/10.1016/j.atherosclerosis.2016.05.023.

[20] J. Besseling, J.B. Reitsma, D. Gaudet, D. Brisson, J.J.P. Kastelein, et al., Selection of individuals for genetic testing for familial hypercholesterolaemia: development and external validation of a prediction model for the presence of a mutation causing familial hypercholesterolaemia, Eur. Heart J. 36 (2016) 2863-2913, http://dx.doi.org/10.1093/eurheartj/ehw135.

[21] S.F.W. Santos RD, A.C.M. Gagliardi, H.Z. Xavier, A. Casella Filho, D.B. Araújo, et al., I Diretriz Brasileira de Hipercolesterolemia Familiar (HF), Rev. Da Soc. Bras. Cardiol. 99 (2012), http://dx.doi.org/10.5935/abc.20120202.

[22] J. Wang, J.S. Dron, M.R. Ban, J.F. Robinson, A.D. McIntyre, et al., Polygenic versus monogenic causes of hypercholesterolemia ascertained clinically, Arterioscler. Thromb. Vasc. Biol. 36 (2016) 2439-2445, http://dx.doi.org/ 10.1161/ATVBAHA.116.308027.

[23] E.M. Degoma, Z.S. Ahmad, E.C. O'Brien, I. Kindt, P. Shrader, et al., Treatment gaps in adults with heterozygous familial hypercholesterolemia in the United States, Circ. Cardiovasc. Genet. 9 (2016) 240-249, http://dx.doi.org/10.1161/ CIRCGENETICS.116.001381. 